\title{
Heart Rate Variability Changes in the Integrated Yoga Program: Results and Implications
}

\author{
Gilija Bernotienė $\dot{1}^{1}$, Selen Razon ${ }^{2}$, Algẻ Daunoravičiené ${ }^{1}$, \\ Alfonsas Vainoras ${ }^{1}$, Agnè Slapšinskaitė ${ }^{1}$ \\ Lithuanian University of Health Sciences ${ }^{1}$, Kaunas, Lithuania \\ West Chester University², West Chester, USA
}

\begin{abstract}
Background. Different methods are used to study cardiovascular parameters. Of these, heart rate variability (HRV) is a relevant marker for both athletes and physically active people. With regards to physical activity, yoga has become a popular form of activity in the recent years. In fact, research has indicated that yoga is a useful modality for both the management and prevention of several cardiovascular conditions. The purpose of the current study was to observe HRV dynamics in young women during a 6-month yoga intervention.

Methods. We recruited 13 women from multiple yoga studios. All participants were practicing Hatha yoga 2 times a week for 6 months. Data were collected: a) at baseline, b) 2 months after the yoga intervention, c) 4 months after the intervention and d) 6 months after the intervention. We used wireless Bluetooth electrocardiogram (ECG) recording device. ECG HRV parameters and heart rate (HR) were used for data analysis.

Results. HR dynamics showed no differences during the 6-month yoga intervention. Meanwhile, vLF parameter after relaxation and LF/HF ratio after body scan meditation significantly changed after yoga intervention. No changes were observed in LF or HF parameter dynamics.

Conclusion. Our results suggest that 6 months twice per week yoga practice influences vLF and LF/HF ratio, especially during relaxation and body scan meditation. We also suggest that healthy women could benefit from practicing body scan meditation. In conclusion, through modification of emotion reactivity, regular practice of yoga can help improve stress response and offset negative consequences associated with the stress process.
\end{abstract}

Keywords: yoga, heart rate variability, women's health, ECG, stress.

\section{INTRODUCTION}

$\mathrm{D}$ ifferent methods are used to study cardiovascular parameters. Of these, heart rate variability (HRV) is a relevant marker for both athletes (Morales et al., 2013) and physically active individuals. With regards to physical activity, yoga has become a popular form of activity in the recent years (Clarke \& Black, 2015). As such, researchers have investigated both physiological and psychological aspects of yoga practice (Kwok, Kwan, Auyeung, Mok, \& Chan, 2017; Rocha et al., 2012). Findings from these studies have suggested that yoga practice increases parasympathetic tone and reduces depression symptoms (Chu et al., 2017). Consequently, the practice of yoga may facilitate a better quality of life due to the management of cardiovascular and psychological states and prevention of potential conditions and diseases.

Pertaining to diseases, cardiovascular conditions remain the leading causes of health impairment among women (Boardman et al., 2015; Garcia, Mulvagh, Merz, Buring, \& Manson, 2016). Furthermore, cardiovascular diseases are often associated with other conditions such as migraine (Kurth et al., 2016; Willett et al., 2015). As a result, alternative and non-conventional approaches to treat cardiovascular conditions exist. Some of these include hormone therapy (Boardman et al., 2015), 
healthy lifestyle programs (Willett et al., 2015) and/or strength training (Shiroma et al., 2016). However, while some physical activities increase risks for developing cardiovascular diseases, others including running (Chalfoun et al., 2015), swimming, cycling or aerobics (Oja et al., 2017) reduce risks of establishing these. Of specific interest herein, practice of yoga was also recognized for reducing the risks of cardiovascular diseases (Chu, Gotink, Yeh, Goldie, \& Hunink, 2014). In fact, research has indicated that yoga is a useful modality for both the management and prevention of several cardiovascular conditions (Chu, 2016).

Concerning the assessment of cardiovascular states, electrocardiogram (ECG) remains a noninvasive and reliable technique (Waechter, 2012). Most commonly measured ECG parameters include RR or JT interval as well as HRV parameters (Chu, Lin, Wu, Chang, \& Lin, 2015; Rohila, 2015; Ziaukas, Alabdulgader, Vainoras, Navickas, \& Ragulskis, 2017). Of these, HRV is a fluctuation between adjacent heartbeats (i.e., RR intervals) and is associated with both sympathetic and parasympathetic activities (Muralikrishnan, Balakrishnan, Balasubramanian, \& Visnegarawla, 2012; Shaffer \& Ginsberg, 2017). Relevant to the present study, changes in HRV during yoga practice were studied based on HRV and its relationship to both cardiovascular and neurological outcomes (Chu et al., 2015, 2017; Papp, Lindfors, Storck, \& Wändell, 2013). The purpose of the current study was to observe HRV dynamics in young women during a 6-month yoga intervention.

\section{METHODS}

Participants. We recruited 13 women from multiple yoga studios. Inclusion criteria were as follows: a) women aged from 18 to 45 years, b) practicing Hatha yoga 2 times a week, c) normal blood pressure (BP) (systolic $\mathrm{BP} \leq 130 \mathrm{mmHg}$ or diastolic $\mathrm{BP} \leq 85 \mathrm{mmHg}$ ), d) normal body weight: body mass index (BMI) from 18.5 to 24.9, e) in premenopausal phase, and f) normal QRS duration $(<.12 \mathrm{~ms})$. The exclusion criteria were as follows: a) any contraindications for physical activity, b) medication use that affects heart rate $(\mathrm{HR})$ or BP c) medication use that prolongs the QT (i.e., antibiotics), antihistamines, appetite suppressants (i.e., fenfluramine), decongestants, psychotropics/antidepressants/anticonvulsants (i.e., antidepressants) d) pregnancy, e) coronary artery disease, f) resting ST-segment (segment between the S-wave and T-wave on the electrocardiogram) depression $>1 \mathrm{~mm}, \mathrm{~g}$ ) left ventricular hypertrophy, h) ST/T changes, and i) QRS complex fragmentation. There were no ectopic or missed beats in participants' ECG.

Measures were presented as means and standard deviations (mean $\pm S D$ ). Participants' $(n=$ $13 ; M_{\text {age }} 31.31 \pm 6.12$ years) measurements included BMI $\left(21.47 \pm 1.58 \mathrm{~kg} / \mathrm{m}^{2}\right)$, systolic BP $(113.46 \pm$ $9.78 \mathrm{mmHg})$; diastolic BP $(71.85 \pm 7.82 \mathrm{mmHg})$, and resting HR $(67.49 \pm 9.01 \mathrm{bpm})$.

This study's protocol was approved by Kaunas Regional Biomedical Research Ethics Committee (BE-2-36) and adhered to the tenets of the Declaration of Helsinki. All of the risks and nature of the experiment were explained to each participants and written consent was signed by all women participating in this study.

Measures. Data were collected: a) at baseline, b) 2 months after the yoga intervention, c) 4 months after the intervention and d) 6 months after the intervention. We used wireless Bluetooth 10-lead ECG recorder M-Trace PC (M4Medical, Lublin, Poland) for ECG recording (Suligowska et al., 2018). ECG HRV parameters and HR were used for analysis. HRV power spectrum was obtained via a fast Fourier transformation (FFT) algorithm using an appropriate software program (Kaunas Load, Lithuanian University of Health Sciences, Institute of Cardiology, Lithuania; Saunoriene et al., 2019). The spectral analysis of HRV was performed using the FFT method in the following bands of frequency: vLF $(0.0033-0.04 \mathrm{~Hz}), \mathrm{LF}(0.04-0.15 \mathrm{~Hz})$ and HF (0.15-0.4 Hz; Suligowska et al., 2018).

Procedures. Similarly to previous work (Yang \& James, 2016), in the course of the 6-month yoga practice, cardiovascular parameters were assessed by means of ECG screenings. Screenings took place every 2 months: at baseline, 2, 4, and 6 months following the regular (2 times a week) yoga practice. Each ECG screenings took approximately 1 hour to complete for each participant. At baseline, during their first visit, participants signed the informed consent form. Next, electrodes were attached to participants' skin to prepare for ECG screening. First two electrodes were placed bilaterally under midclavicular points and other four electrodes were placed $1 \mathrm{~cm}$ above the left lower costal margin. Finally, the last four electrodes were placed bilaterally on participants' mid scapular region and bilaterally above mid iliac crest. Participants 


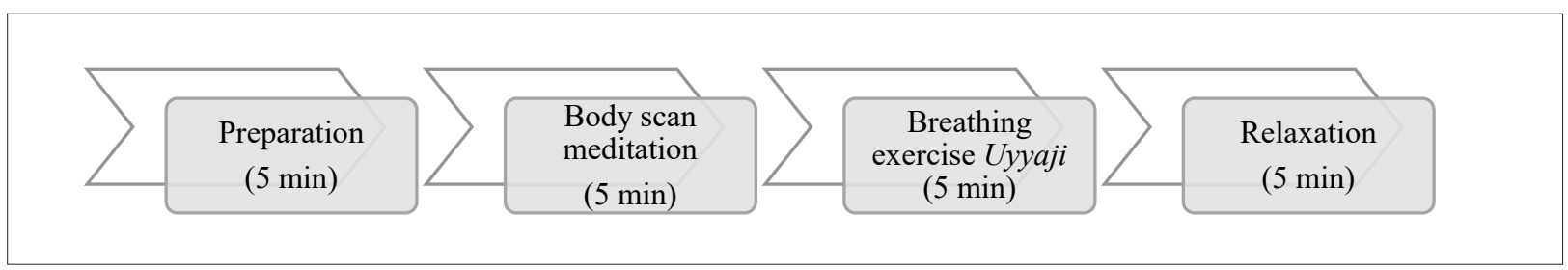

Figure 1. ECG screening procedure

were instructed to relax in a supine position for 20 minutes while the four phases of ECG screening were recorded: rest in preparation, body scan meditation, Uyyaji breathing exercise and relaxation (see Figure 1). In previous yoga research, relaxation in supine position and Uyyaji breathing exercise (Novakovi, Pavlovi, \& Milovanovi, 2011) were commonly used as well (Bhavanani, Raj, Ramanathan, \& Trakroo, 2016).

Yoga program. During a 6-month period, yoga practice was led by a certified yoga teacher (with 10 years of experience). Each practice involved a different sequence and lasted a total of 90 minutes. Each practice included 5 minutes of pranayama (i.e., breathing exercises), 15 minutes of warm-up, 60 minutes of asana (i.e., yoga pose) practice, and 10 minutes of Savasana (i.e., meditation/relaxation; Chu etal., 2017). Yoga poses were adapted to suit each participants' body type and individual needs. Most commonly used yoga poses included: Sukhasana (Easy sitting pose), Tadasana (Mountain pose), Adho Mukha Svanasana (Downward Facing Dog), Bhujangasana (Cobra pose), Virabhadrasana I, II and III (Warriors 1,2 and 3), Trikonasana (Triangle pose), Vrksasana (Tree Pose), Marjaryasana (Cat Pose), Balasana (Child's Pose) and Savasana (Corpse Pose). Specific emphasis was placed upon breathing and balancing movement with breath. Also, participants were instructed not to force on achieving particular poses but rather to focus on the overall practice itself.

Data analysis. Data analysis was computed using IBM SPSS Statistics 22.0 (IBM Corp., Chicago, IL, USA) and Microsoft Excel 2017. The difference between ECG screening sessions was tested using non-parametric Friedman's test because the assumption of normality was not met since the sample size was small. Values were presented as mean \pm standard deviation (mean \pm $S D$ ) and differences were considered statistically significant when values approached $p<.05$ level.

\section{RESULTS}

All participants reported a high level of commitment to the regular yoga practices as well as the ECG screenings. HR dynamics is presented in Figure 2. After rest in preparation, HR dynamics changed from $67.49 \mathrm{bpm}$ at baseline to $68.05 \mathrm{bpm}$ after 6 months $\left(\chi^{2}(3)=1.34, p=.720\right)$. Body scan meditation led to a decrease from HR $68.01 \mathrm{bpm}$ at baseline to $66.59 \mathrm{bpm}$ after 6 months of practice $\left(\chi^{2}(3)=1.15, p=.764\right)$. HR was $74.44 \mathrm{bpm}$ at baseline and $70.49 \mathrm{bpm}$ after 6 months following breathing exercise $\left(\chi^{2}(3)=3.74, p=.291\right)$. HR changed from $67.93 \mathrm{bpm}$ at baseline to $66.50 \mathrm{bpm}$ after relaxation $\left(\chi^{2}(3)=0.79, p=.853\right)$.

As seen in Figure 3, during rest in preparation, vLF parameter fluctuated from $-.71 \mathrm{Tg}(\mathrm{a})$ at baseline to $-.60 \mathrm{Tg}(\mathrm{a})$ after 6 months $\left(\chi^{2}(3)=0.21, p=.976\right)$. Body scan meditation showed different results of vLF parameter. At baseline vLF parameter was $0.33 \operatorname{Tg}(a)$ and after 6 months was $-0.54 \operatorname{Tg}(a)$ $\left(\chi^{2}(3)=4.81, p=.186\right)$. After breathing exercise, $\mathrm{vLF}$ parameter reached the level of $-0.38 \operatorname{Tg}(\mathrm{a})$ at baseline while $-0.36 \operatorname{Tg}\left(\right.$ a) after 6 months $\left(\chi^{2}(3)=\right.$ 2.63, $p=.452)$. Finally, a difference was observed in $\mathrm{vLF}-0.37 \mathrm{Tg}(\mathrm{a})$ at baseline and $-0.81 \mathrm{Tg}$ (a) after relaxation $\left(\chi^{2}(3)=17.12, p=.001\right)$.

Data for HRV LF parameter is presented in Figure 4. During rest in preparation, LF parameter fluctuated from $0.17 \operatorname{Tg}(\mathrm{a})$ at baseline to $0.54 \mathrm{Tg}(\mathrm{a})$ after 6 months $\left(\chi^{2}(3)=2.08, p=.557\right)$. Body scan meditation results of LF parameter at baseline were $-.49 \operatorname{Tg}(\mathrm{a})$ and after 6 months were $-.14 \operatorname{Tg}(\mathrm{a})$ $\left(\chi^{2}(3)=2.72, p=.437\right)$. LF parameter was -0.04 $\operatorname{Tg}(\mathrm{a})$ at baseline and $0.22 \operatorname{Tg}$ (a) after 6 months following breathing exercise $\left(\chi^{2}(3)=1.15, p=.764\right)$. LF parameter fluctuated from $.32 \mathrm{Tg}(\mathrm{a})$ at baseline to $0.40 \mathrm{Tg}(\mathrm{a})$ after relaxation $\left(\chi^{2}(3)=0.97, p=.809\right)$.

Figure 5 presents results of HRV HF parameter dynamics. HF parameter of rest in preparation showed fluctuations from $-0.97 \mathrm{Tg}(\mathrm{a})$ at baseline to 


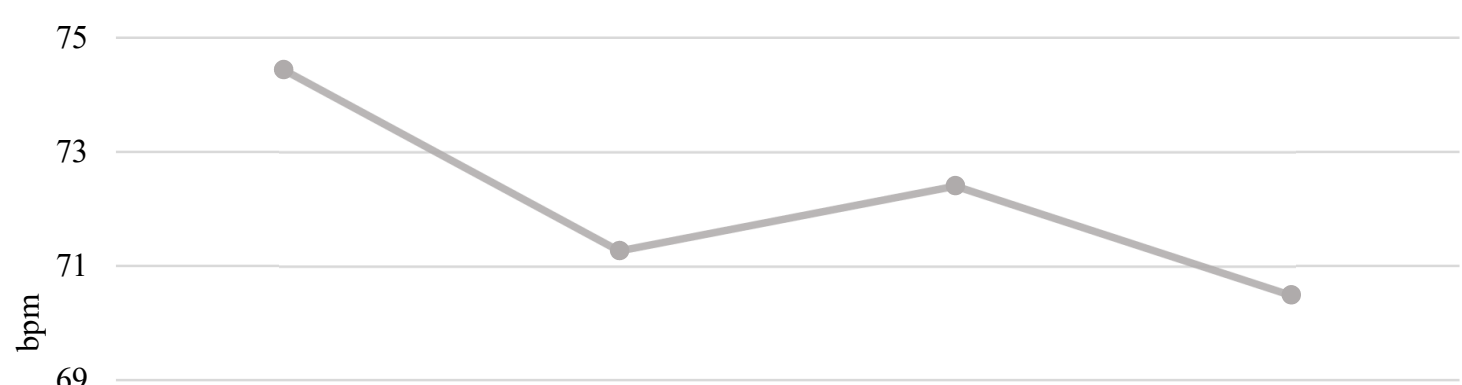

67

65

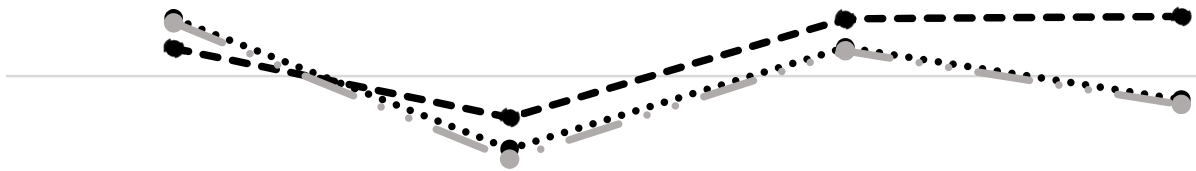

Screening 1

(baseline)

\section{Screening 2} (after 2 months)
Screening 3

(after 4 months)
Screening 4 (after 6 months)

- - HR dynamics after preparation

••. HR dynamics after body scan meditation

$\longrightarrow$ HR dynamics after breathing exercise HR dynamics after relaxation

Figure 2. HR dynamics during 6-month period

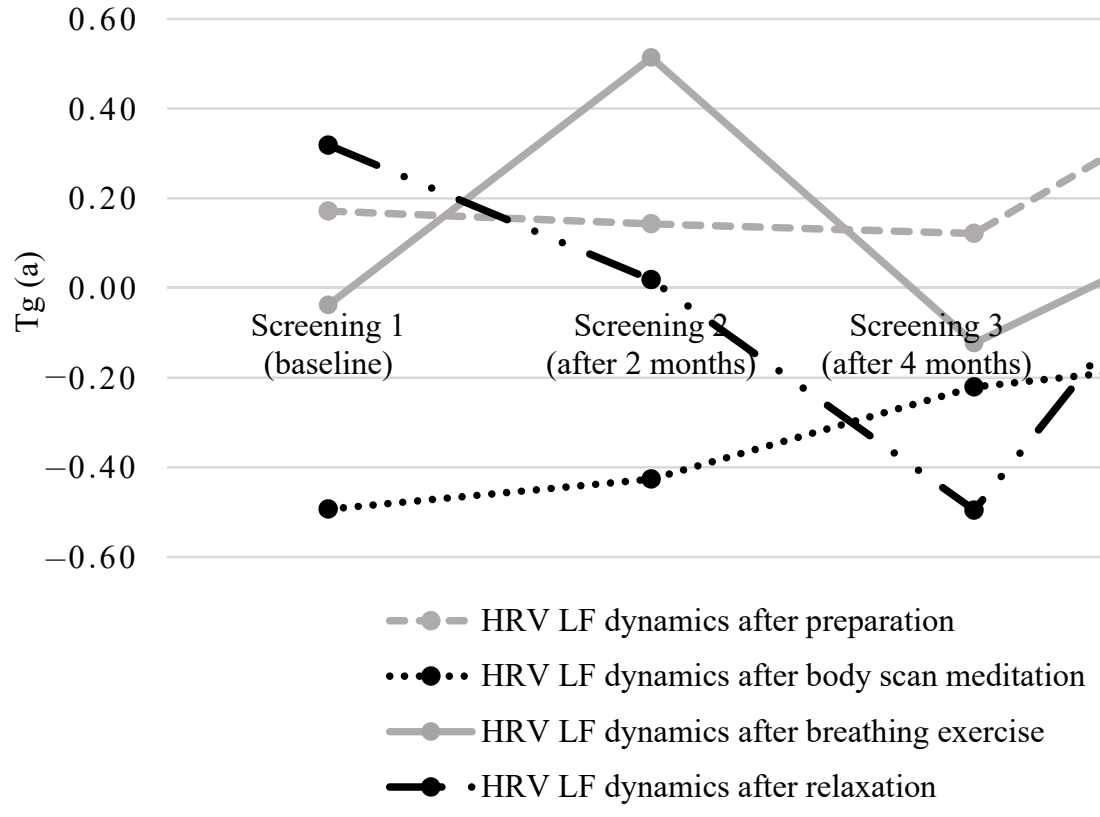

Figure 3. HRV vLF dynamics during 6-month period

$-1.22 \operatorname{Tg}$ (a) after 6 months $\left(\chi^{2}(3)=7.43, p=.059\right)$. Also, results of $\mathrm{HF}$ parameter at baseline were $-1.13 \operatorname{Tg}(\mathrm{a})$ and after 6 months were $-1.08 \operatorname{Tg}(\mathrm{a})$ after body scan meditation $\left(\chi^{2}(3)=2.77, p=.429\right)$. In addition to this, HF parameter differed from
$-1.03 \operatorname{Tg}$ (a) at baseline to $-0.91 \operatorname{Tg}($ a) after 6 months after breathing exercise $\left(\chi^{2}(3)=0.98, p=.805\right)$. HF parameter dynamics changed from $-1.01 \operatorname{Tg}(\mathrm{a})$ at baseline to $-1.38 \operatorname{Tg}\left(\right.$ a) after relaxation $\left(\chi^{2}(3)=1.62\right.$, $p=.655)$. 


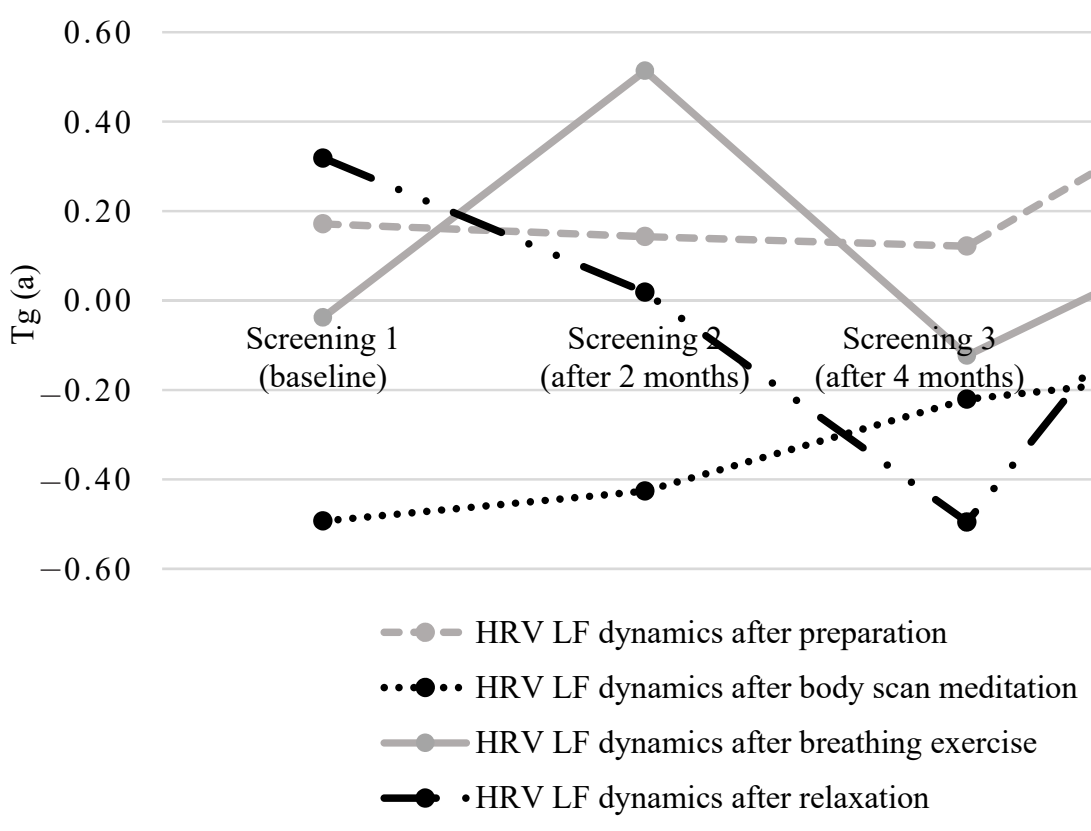

Figure 4. HRV LF dynamics during 6-month period

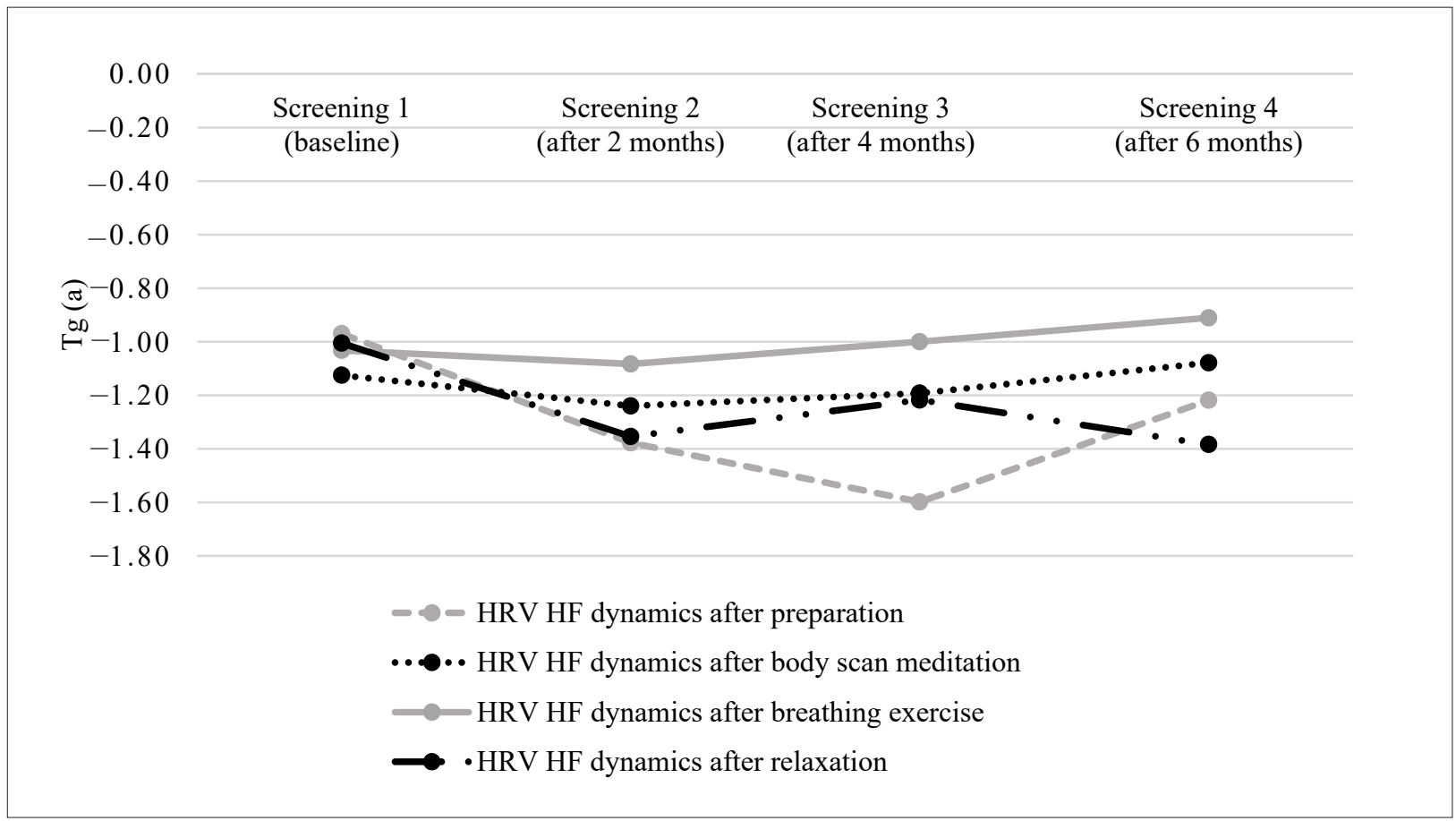

Figure 5. HRV HF dynamics during 6-month period

Figure 6 presents LF/HF ratio dynamics. Rest in preparation demonstrated $\mathrm{LF} / \mathrm{HF}$ baseline ratio of 0.86 , with a decrease to $0.66\left(\chi^{2}(3)=4.58, p=.205\right)$ after 6 months. Following body scan meditation LF/ HF ratio changed from .70 at baseline to .63 after 6 months $\left(\chi^{2}(3)=7.84, p=.049\right)$. LF/HF ratio was 1.28 at baseline and 1.55 after 6 months following breathing exercise $\left(\chi^{2}(3)=0.88, p=.831\right)$ LF/HF ratio dynamics fluctuated from .80 at baseline to .83 after relaxation $\left(\chi^{2}(3)=1.22, p=.749\right)$. 


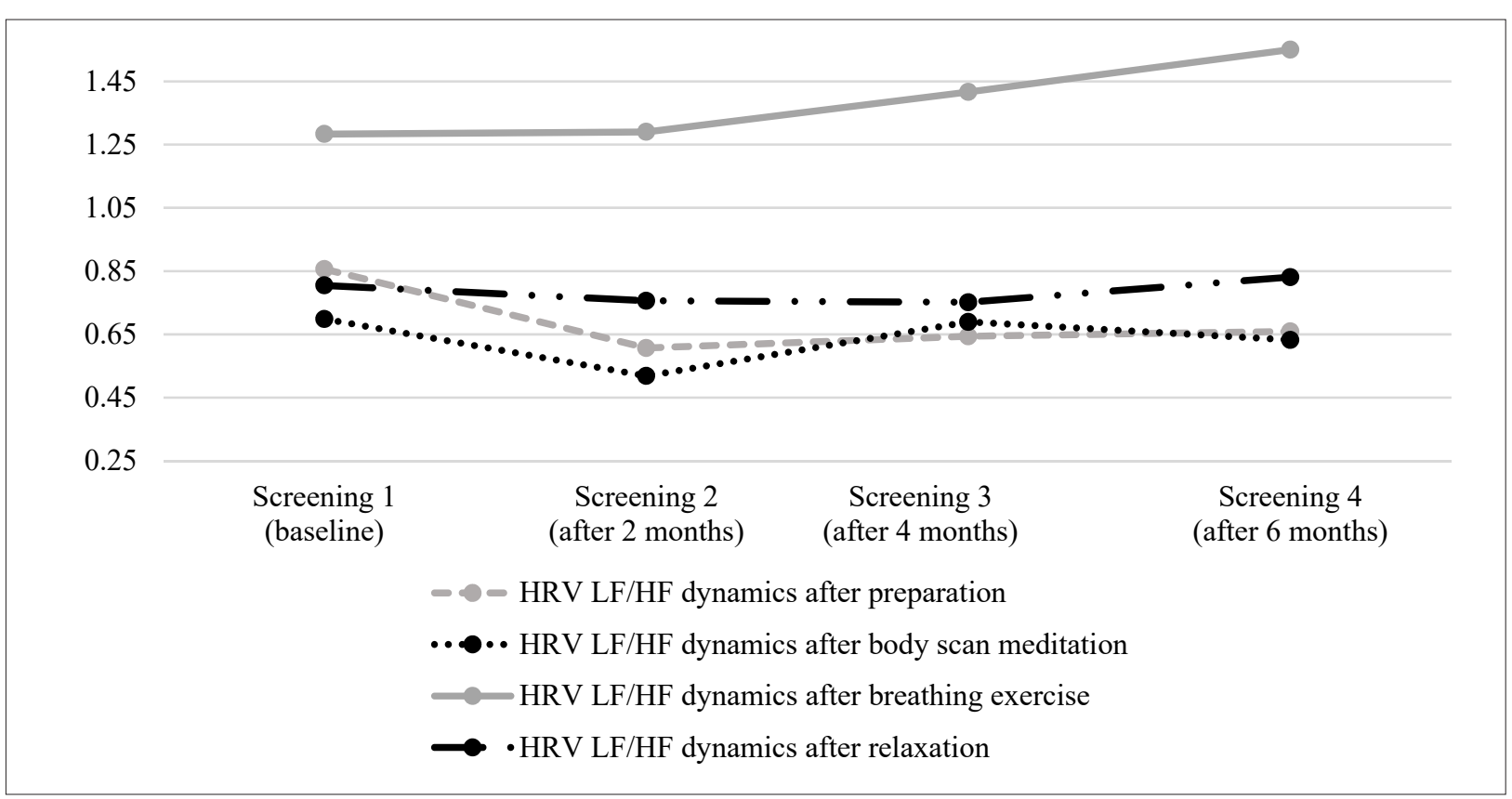

Figure 6. HRV LF/HF dynamics during 6-month period

\section{DISCUSSION}

The present findings reflect the combined effects of low intensity exercise with meditation and breath control that are typically intertwined in yoga practice (Benvenutti et al., 2017). The main finding of this study revealed that vLF differed in relaxation and $\mathrm{LF} / \mathrm{HF}$ ratio changed in body scan meditation after 6 months in comparison to baseline. While there were changes with regards to HR, vLF, LF, HF, LF/HF ratio, after rest in preparation, body scan meditation, breathing exercise and relaxation significant changes were only present in body scan meditation and relaxation.

These findings are at least partially consistent with the previous ones suggesting that HRV parameters (i.e., $\mathrm{HF}, \mathrm{LF}$, and $\mathrm{LF} / \mathrm{HF}$ ) do not differ between individuals practicing yoga and control groups (Chu et al., 2015). Specifically, in the course of an 8-week yoga program practiced twice a week, 60 minutes per session, there was no significant improvement in HRV (Chu et al., 2015). Therefore, this is one of the first studies to reveal that a 6-month yoga practice can lead to changes in VLF and LF/ $\mathrm{HF}$ ratio. Some of previous work has used the LF/ HF ratio to quantify the degree of sympathovagal balance (Rosenberg, Chanwimalueang, Adjei, \& Jaffer, 2017) while some others have used the vLF band to indicate sympathovagal balance (Usui \& Nishida, 2017). Earlier studies have also shown that voluntary breathing exercises with varying frequency, depth, and pauses can help modulate cardiovascular sympathovagal oscillations (Novak et al., 1993; Subbalakshmi, Basha, \& Ramesh, 2009). To that end, it is also important to note that positive reactions may emerge since $\mathrm{LF} / \mathrm{HF}$ is sensitive to psychological stress and was previously was used as a marker in a number of studies (Malliani et al., 1997; Montano et al., 1994; Rådmark, Sidorchuk, \& Osika, 2019).

Contrary to our findings, some of the previous work examining the $\mathrm{LF} / \mathrm{HF}$ ratio releveled significant decreases in the ratio in the course of a SKY (Sudarshan Kriya) program. A SKY program involves slow Ujjayi breathing (diaphragmatic breathing) with inhalatory and exhalatory pauses, followed by fast-paced Bhastrika pranayama (rapid breathing) and cyclic rhythmic breathings. The breathings in a SKY program occur in slow, medium, and fast frequencies (Bhaskar, Kharya, Deepak, \& Kochupillai, 2017).

For an accurate interpretation of the current findings, two limitations should be considered: (a) 
first, despite statistical significance our conclusions are not applicable to menopausal women or women with specific conditions such as those with high levels of anxiety and stress and/or with chronic respiratory diseases including chronic nasal congestion or obstruction Therefore, our results should be generalized with caution, (b) additional studies with alternative yoga poses or varying protocols are needed to advance the knowledge on the acute cardiovascular effects of these poses by measuring not only HR, vLF, LF, HF, LF/HF ratio, but also additional ECG parameters, for instance including ST amplitude, QRS, and JT intervals. Hence, the current findings do not speak to the outcomes of one specific yoga method (i.e., Surya Namaskar, Kapalabhati breathing exercise) but rather a combination of different methods.

\section{CONCLUSIONS}

The purpose of the current study was to investigate HRV dynamics in young women during a 6-month yoga intervention. Specifically, this remains among the first attempts to explore the cardiovascular dynamics during a long-term (6-month) twice per week yoga practice assessed at 2-months intervals. Our results suggest that 6 months twice per week yoga practice can help affect the vLF and LF/HF ratio, especially while performing relaxation and body scan meditation components.

From a practical standpoint, our findings suggest that healthy women could benefit from practicing body scan meditation as the meditation seems to increases the effect of HF parameter that in turn helps decrease $\mathrm{LF} / \mathrm{HF}$ ratio as a stronger influence of the parasympathetic nervous system. This said, it is important to note that the parasympathetic nervous system gets activated once individuals are at rest (Ming et al., 2019). The latter is especially important with regards to coping with stress and resilience in the course of stressful situations. In conclusion, then, through modification of emotional reactivity, regular practice of yoga can help improve stress response and offset negative consequences associated with the stress process.

Acknowledgments. Gilija Bernotiene is the recipient of a predoctoral fellowship and this study was supported by Lithuanian University of Health Sciences (MC9-52). This research was further supported by The Institute of Cardiology at Lithuanian University of Health Sciences The funders had no role in study design, data collection and analysis, decision to publish, or preparation of the manuscript. We would also like to thank all the participants who took part in this study.

Author disclosure statement. The authors declare no conflict of interest.

\section{REFERENCES}

Benvenutti, M. J., Alves, E. da S., Michael, S., Ding, D., Stamatakis, E., \& Edwards, K. M. (2017). A single session of hatha yoga improves stress reactivity and recovery after an acute psychological stress task - A counterbalanced, randomized-crossover trial in healthy individuals. Complementary Therapies in Medicine, 35(October 2017), 120-126. https://doi.org/10.1016/j. ctim.2017.10.009

Bhaskar, L., Kharya, C., Deepak, K. K., \& Kochupillai, V. (2017). Assessment of cardiac autonomic tone following long Sudarshan Kriya yoga in art of living practitioners. The Journal of Alternative and Complementary Medicine, 23(9), 705-712. https://doi.org/10.1089/acm.2016.0391

Bhavanani, A. B., Raj, J. B., Ramanathan, M., \& Trakroo, M. (2016). Effect of different pranayamas on respiratory sinus arrhythmia. Journal of Clinical and Diagnostic Research, 10(3), CC04-CC06. https://doi. org/10.7860/JCDR/2016/16306.7408

Boardman, H., Hartley, L., Eisinga, A., Main, C., Roqué Figuls, M., Bonfill Cosp, X., ... Knight, B. (2015).
Hormone therapy for preventing cardiovascular disease in post-menopausal women. Cochrane Database System Review, 3. https://doi.org/10.1002/14651858.CD002229. pub4

Chalfoun, C., Karelis, A. D., Stip, E., \& Abdel-Baki, A. (2016). Running for your life: A review of physical activity and cardiovascular disease risk reduction in individuals with schizophrenia. Journal of Sports Sciences, 34(16), 1500-1515. https://doi.org/10.1080/02 640414.2015.1119875

Chomistek, A. K., Chiuve, S. E., Eliassen, A. H., Mukamal, K. J., Willett, W. C., \& Rimm, E. B. (2015). Healthy lifestyle in the primordial prevention of cardiovascular disease among young women. Journal of the American College of Cardiology, 65(1), 43-51. https://doi.org/10.1016/j.jacc.2014.10.024

Chu, I.-H., Lin, Y.-J., Wu, W.-L., Chang, Y.-K., \& Lin, I.-M. (2015). Effects of yoga on heart rate variability and mood in women: A randomized controlled trial. The Journal of Alternative and Complementary Medicine, 
21(12), 789-795.https://doi.org/10.1089/acm.2015.0138 Chu, I.-H., Wu, W.-L., Lin, I.-M., Chang, Y.-K., Lin, Y.-J., \& Yang, P.-C. (2017). Effects of yoga on heart rate variability and depressive symptoms in women: A randomized controlled trial. The Journal of Alternative and Complementary Medicine, 23(4), 310-316. https:// doi.org/10.1089/acm.2016.0135

Chu, P., Gotink, R. A., Yeh, G. Y., Goldie, S. J., \& Hunink, M. M. (2016). The effectiveness of yoga in modifying risk factors for cardiovascular disease and metabolic syndrome: A systematic review and metaanalysis of randomized controlled trials. European Journal of Preventive Cardiology, 23(3), 291-307. https://doi.org/10.1177/2047487314562741

Chu, P. N.-T. (2016). Identifying high-value lifestyle interventions for cardiovascular disease prevention. Harvard.

Cl Clarke, T. C., Black, L. I., Stussman, B. J., Barnes, P. M., \& Nahin, R. L. (2015). Trends in the use of complementary health approaches among adults: United States, 2002-2012. National Health Statistics Reports, 10(79), 1-16.

Garcia, M., Mulvagh, S. L., Bairey Merz, C. N., Buring, J. E., \& Manson, J. E. (2016). Cardiovascular disease in women: Clinical perspectives. Circulation Research, 118(8), 1273-1293. https://doi.org/10.1161/ CIRCRESAHA.116.307547

Kurth, T., Winter, A. C., Eliassen, A. H., Dushkes, R., Mukamal, K. J., Rimm, E. B., ... Rexrode, K. M. (2016). Migraine and risk of cardiovascular disease in women: Prospective cohort study. BMJ, 353(2610), 1-6. https:// doi.org/10.1136/bmj.i2610

Kwok, J. J. Y. Y., Kwan, J. C. Y., Auyeung, M., Mok, V. C. T., \& Chan, H. Y. L. (2017). The effects of yoga versus stretching and resistance training exercises on psychological distress for people with mild-tomoderate Parkinson's disease: Study prxotocol for a randomized controlled trial. Trials, 18(1), 1-13. https:// doi.org/10.1186/s13063-017-2223-x

Malliani, A., Pagani, M., Furlan, R., Guzzetti, S., Lucini, D., Montano, N., ... Mela, G. S. (1997). Individual recognition by heart rate variability of two different autonomic profiles related to posture. Circulation, 96(12), 4143-4145. https://doi.org/https:// doi.org/10.1161/01.CIR.96.12.4143

Ming, Y., Shyh, C., Lou, L., Zhe, P., Ming, T., \& Wang, C. (2019). The efficacy of respiratory regulation on parasympathetic nervous system appraised by heart rate variability. Journal of Medical and Biological Engineering, 39(6), 960-966. https://doi.org/10.1007/ s40846-019-00472-z

Montano, N., Ruscone, T. G., Porta, A., Lombardi, F., Pagani, M., \& Malliani, A. (1994). Power spectrum analysis of heart rate variability to assess the changes in sympathovagal balance during graded orthostatic tilt. Circulation, 90(4), 1826-1831. https://doi. org/10.1161/01.cir.90.4.1826
Morales, J., Garcia, V., García-Massó, X., Salvá, P., Escobar, R., \& Buscà, B. (2013). The use of heart rate variability in assessing precompetitive stress in high-standard judo athletes. International Journal of Sports Medicine, 34(2), 144-151. https://doi. org/10.1055/s-0032-1323719

Muralikrishnan, K., Balakrishnan, B., Balasubramanian, K., \& Visnegarawla, F. (2012). Measurement of the effect of Isha Yoga on cardiac autonomic nervous system using short-term heart rate variability. Journal of Ayurveda and Integrative Medicine, 3(2), 91-96https://doi. org/10.4103/0975-9476.96528

Novaković, B., Pavlović, S., \& Milovanović, B. (2011). Autonomous control of cardiovascular function in yoga instructors and effects of energetic renewal on modulation of autonomic function. International Scientific Yoga Journal: Sense, 1(1), 99-109.

Novak, V., Novak, P., de Champlain, J., Le Blanc, A. R., Martin, R., \& Nadeau, R. (1993). Influence of respiration on heart rate and blood pressure fluctuations. Journal of Applied Physiology, 74(2), 617-626. https://doi. org/10.1152/jappl.1993.74.2.617

Oja, P., Kelly, P., Pedisic, Z., Titze, S., Bauman, A., Foster, C., ... \& Stamatakis, E. (2017). Associations of specific types of sports and exercise with all-cause and cardiovascular-disease mortality: A cohort study of 80306 British adults. British Journal of Sports Medicine, 51(10), 812-817.. https://doi.org/10.1136/ bjsports-2016-096822

Papp, M. E., Lindfors, P., Storck, N., \& Wändell, P. E. (2013). Increased heart rate variability but no effect on blood pressure from 8 weeks of hatha yoga - a pilot study. BMC Research Notes, 6, 59. https://doi. org/10.1186/1756-0500-6-59

Rådmark, L., Sidorchuk, A., \& Osika, W. (2019). A Systematic review and meta-analysis of the impact of mindfulness based interventions on heart rate variability and inflammatory markers. Journal of Clinical Medicine, 8(10), 1638. https://doi.org/10.3390/jcm8101638

Rocha, K. K. F., Ribeiro, A. M., Rocha, K. C. F., Sousa, M. B. C., Albuquerque, F. S., Ribeiro, S., \& Silva, R. H. (2012). Improvement in physiological and psychological parameters after 6months of yoga practice. Consciousness and Cognition, 21(2), 843-850. https:// doi.org/10.1016/j.concog.2012.01.014

Rohila, A. (2015). A novel approach for detection of RRIinterval. International Journal of Combined Research \& Development (IJCRD), 4(6), 618-621.

Rosenberg, W. Von, Chanwimalueang, T., Adjei, T., \& Jaffer, U. (2017). Resolving ambiguities in the LF / HF Ratio: LF-HF Scatter Plots for the categorization of mental and physical stress from HRV. Frontiers in Physiology, 8, 1-12. https://doi.org/10.3389/fphys.2017.00360

Saunoriene, L., Siauciunaite, V., Vainoras, A., Bertasiute, V., Navickas, Z., \& Id, M. R. (2019). The characterization of the transit through the anaerobic threshold based on relationships between RR and QRS cardiac intervals. PLoS 
ONE, 14(5), 1-14. https://doi.org/https://doi.org/10.1371/ journal.pone.0216938

Shaffer, F., \& Ginsberg, J. P. (2017). An overview of heart rate variability metrics and norms. Frontiers in Public Health, 5, 1-17. https://doi.org/10.3389/ fpubh.2017.00258

Shiroma, E. J., Cook, N. R., Manson, J. E., Moorthy, M. V., Buring, J. E., Rimm, E. B., \& Lee, I. M. (2017). Strength training and the risk of type 2 diabetes and cardiovascular disease. Medicine and Science in Sports and Exercise, 49(1), 40. https://doi.org/10.1249/ MSS.0000000000001063

Subbalakshmi, N. K., Basha, A., \& Ramesh, B. (2009). Impact of acute respiratory stress on cardiac autonomic control in young healthy subjects explored by time and frequency domain methods. The Chinese Journal of Physiology, 52(5), 299-305.

Suligowska, K., Czarniak, P., Krawczyk, M., Szcześniak, P., Król, E., Kusiak, A., ... Zdrojewski, T. (2018). An assessment of health status and health behaviours in adolescents: Main points and methods of the SOPKARDJunior programme. Archives of Medical Science, 14(1), 38-51. https://doi.org/10.5114/aoms.2016.63742

Usui, H., \& Nishida, Y. (2017). The very low-frequency band of heart rate variability represents the slow recovery component after a mental stress task. PloS One, 12(8), 1-9. e0182611.. https://doi.org/10.5061/dryad.7pn71. Funding

Waechter, J. (2012). Introduction to ECG's: Rhythm Analysis. Retrieved from www.teachingmedicine.com/ pdf_files/ECG_Intro.pdf

Yang, K., \& James, K. A. (2016). Yoga, as a transitional platform to more active lifestyle: A 6-month pilot study in the USA. Health Promotion International, 31(2), 423-429. https://doi.org/10.1093/heapro/dau108

Ziaukas, P., Alabdulgader, A., Vainoras, A., Navickas, Z., $\&$ Ragulskis, M. (2017). New approach for visualization of relationships between RR and JT intervals. PLoS ONE, 12(4). https://doi.org/10.1371/journal.pone.0174279 